\title{
Experimental Study of a Beta Stirling Thermal Machine Type Functioning in Receiver and Engine Modes
}

\author{
R. Gheith ${ }^{1,2,3}$, F. Aloui ${ }^{\dagger 1,2}$ and S. Ben Nasrallah ${ }^{3}$ \\ ${ }^{1}$ Université de Nantes, Faculté des Sciences et des Techniques, \\ Département de Physique, 2, rue de la Houssinière BP 92208 - 44322, Nantes Cedex 03 - France \\ ${ }^{2}$ GEPEA, CNRS - UMR 6144, DSEE, École des Mine, 4 rue Alfred Kastler - BP20722 - 44307 Nantes Cedex - France \\ ${ }^{3}$ Université de Monastir, École Nationale d'Ingénieurs de Monastir, Laboratoire LESTE, \\ Avenue Ibn El Jazzar 5019, Monastir, Tunisie \\ $\dagger$ Corresponding Author Email: Fethi.Aloui@univ-nantes.fr \\ (Received January 5, 2009; accepted February 24, 2010)
}

\begin{abstract}
In this paper we studied a beta type Stirling machine. At first, we present the adopted theoretical quasi-stationary model. Then, we pass to the physical and geometrical presentation of this machine. The Latter was experimented according to two configurations: motor configuration and receiver configuration. For the first configuration, in order to improve the performances of the machine, we proceeded to the insulation of the machine hot room to reduce losses by radiation. For the second configuration, the machine is experimented as a heat pump and refrigerator. Comparisons between the theoretical and experimental results are also presented. We finally validated the results obtained by the model with experiments.
\end{abstract}

Keywords: Stirling, Motor, Heat pump, Refrigerator, Regenerator, Porous media, Insulation, Heat transfer.

\section{NOMENCLATURE}

\begin{tabular}{llllll}
$A$ & Area & $\mathrm{m}^{2}$ & $\mathrm{~W}$ & Work & $\mathrm{J}$ \\
$C p$ & Specific heat at constant pressure & $\mathrm{J} \mathrm{kg}^{-1} \mathrm{~K}^{-1}$ & $\mathrm{Z}$ & Displacer stroke & $\mathrm{m}$ \\
$C p r$ & Heat capacity of each cell matrix & $\mathrm{W} \mathrm{K}^{-1}$ & \multicolumn{2}{l}{ Subscripts } & \\
$C v$ & Specific heat at constant volume & $\mathrm{J} \mathrm{kg}^{-1} \mathrm{~K}^{-1}$ & $c$ & Compression space & \\
$F$ & Friction force & $\mathrm{N}$ & $d$ & Expansion space & \\
$\mathrm{G}$ & $\begin{array}{l}\text { Convection heat transfer } \\
\text { coefficient }\end{array}$ & $\mathrm{kg}^{-1} \mathrm{~m}^{-2} \mathrm{~s}^{-1}$ & $f$ & Cooler & \\
$H$ & Heat transfer coefficient & & $h$ & Heater & \\
$M$ & Mass of gas in different component & $\mathrm{kg}$ & $P a$ & Wall & \\
$\dot{m}$ & Mass flux rate & $\mathrm{W}$ & $r$ & Regenerator & \\
$P$ & Pressure & $\mathrm{Pa}$ & $r l$ & Regenerator cell 1 & $\mathrm{Density}^{-}$ \\
$Q$ & Heat & $\mathrm{J}$ & $r 2$ & Regenerator cell 1 & $\mathrm{Kg} \mathrm{m}^{-3}$ \\
$\mathrm{R}$ & Gas constant & $\mathrm{J} \mathrm{kg} \mathrm{K}$ & $P$ & & $\mathrm{Kg} \mathrm{m}^{-1} \mathrm{~s}^{-1}$ \\
$\mathrm{~T}$ & Temperature & $\mathrm{K}$ & $\mu$ & Working gas dynamic viscosity \\
$\mathrm{T}$ & Time & $\mathrm{t}$ & $\lambda$ & Thermal conductivity & $\mathrm{W} \mathrm{m}^{-1} \mathrm{~K}^{-1}$ \\
$\mathrm{U}$ & Velocity of the working fluid & $\mathrm{M} \mathrm{s}-1$ & $\Delta P$ & Pressure drops & \\
$\mathrm{V}$ & Volume & $\mathrm{m}$ & & &
\end{tabular}




\section{INTRODUCTION}

The Stirling machine was invented in 1816 by Robert Stirling (Stirling et al. 1816) in Scotland, some 80 years before the invention of diesel machine. It enjoyed substantial commercial success up to the early 1900s. The Stirling cycle machine is a device which operates on a closed regenerative thermodynamic cycle, with cyclic compression and expansion of the working fluid at different temperature levels.

The increasing interest in Stirling machine is due to the fact that machine is simple and safe to operate. It runs almost on any combustible fuel or renewable energy sources. Unlike the internal combustion machine (Pertescu et al. 2002), the Stirling machine is known by its environment friendliness. The absence of explosive nature in converting heat energy into mechanical leads to silent and cleaner operation. Theses characteristics are essential for special applications, such as military operations and medical uses.

Stirling machines are considered the best among the most effective low-power range solar thermal conversion units (Mancini et al. 2003).

Several researchers revealed that the principal impediment to its success is not theoretical analysis, but practical conception and design (Organ et al. 1997).

In fact, the Stirling machine works in closed cycle (Fig. 1). The working fluid trapped in the machine undergoes the following transformations: isothermal compression $(1 \rightarrow 2)$, isochoric heating $(2 \rightarrow 3)$ isothermal expansion $(3 \rightarrow 4)$, isochoric cooling $(4 \rightarrow 1)$.

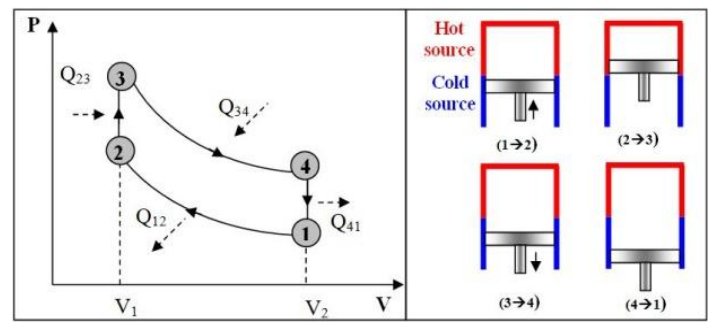

Fig. 1. Theoretical Stirling cycle for motrice machine (Urieli et al. 1982)

Compared to Carnot cycle, Stirling one have same advantages, we note the replacement of two isentropic and two isochoric transformations, which increases considerably the area of Stirling cycle in the $\mathrm{p}-\mathrm{V}$ Clapeyron diagram).

In this cycle, a constant mass of gas (air, helium, or hydrogen) is alternately: relaxed, cooled, compressed and warmed. The processes of heating and cooling are improved appreciably by a regenerator. The regenerator (Nika et al. 1997) is generally a cylinder constituted by a matrix, a porous media or simply an annular crack. It is crossed by the working fluid in the two senses. It works like a thermal sponge witch alternatively absorbs and releases heat. Expansion volume is maintained at high temperature, and compression volume is maintained at low temperature.
Since 1937 (Senft et al. 1993), the Stirling machine was brought to a high state of technological development by the Philips Research Laboratory in Eindhoven, Holland. New materials are considered among the keys to the Stirling machine success.

In 1834, Herschel proposes to use the Stirling machine as receiving machines (Stine et al. 1994). But this project waited till 1861 to be concretized by Kirk (Al-Hazmy et al. 1998). The receiving Stirling cycle was reconsidered in 1946 by Philips Company, to lead to refrigerators reaching temperatures lower than $12 \mathrm{~K}$. In 1957, Finkelsteins and al. (Berchowitz et al. 1998) demonstrated that the Stirling receiving machines have better performances that those produced by the Rankine cycle. Berchowitz et al. (1991) presented a free piston Stirling refrigerator using helium as working gas. This refrigerator appeared very competitive compared to compression steam systems. Berchowitz et al. (1992) optimized a Stirling refrigerator taking into accounts the different irreversibilities, in the purpose to make it operating at intermediate temperatures. The irreversibilities in the Stirling engine are of two forms: internal and external. The internal ones are caused by the internal conductance inside the components of the engine, and due to the non adiabatic regenerator. The external ones are caused by the exchanges between the working fluid and the heat sources. (Popescu et al. 1996).

Currently, the receiving Stirling machines are used in several domains: the metals treatment, the liquefaction of gases, and the sterilization of medical and paramedical materials. The problems of these machines are especially of technical order: use of helium under elevated pressures (problems of tightness), mobile mechanical pieces generating rubbings, internal thermal transfer, efficiency and compactness of the regenerator. In this study, we present firstly a theoretical approach based on the quasi-stationary model. Secondly we explain theoretical and experimental results. We finish by comparing both results and explaining the noted differences.

\section{THEORETICAL APPROACH FOLLOWING THE QUASI-STEADY MODEL}

The theoretical model (Fig. 2) is based on the model proposed by Urieli et al. (1982). The quasi-stationary model takes also into considerations the frictional drag force which generates a pressure drop across each heat exchangers as well as the corresponding dissipation flux of the internal heat. Several hypotheses are considered in this model:

- The working fluid is considered as perfect gas,

- The temperature of the engine walls is assumed as constant,

- The temperature is uniform in the cooler and in the heater, and linear inside the regenerator.

- The heat is transferred to the working fluid by forced convection,

- The temperature of the working fluid is different of that of the associated wall 


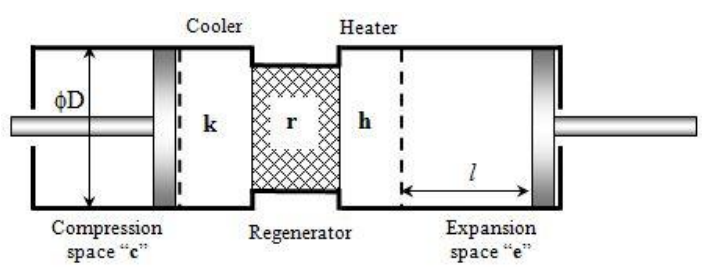

Fig. 2. Schematic design of the Stirling engine with its compartments

The regenerator is divided into two cells $r_{1}$ and $r_{2}$, each cell has been associated with its respective mixed mean gas temperature $T_{r 1}$ and $T_{r 2}$. We consider that the temperature gradient is linear in the regenerator. By considering this hypothesis, the temperatures to the interfaces of the regenerator are calculated as follows:

$$
\begin{aligned}
T_{r 1} & =\frac{P_{r 1} V_{r 1}}{R m_{r 1}} \\
\mathrm{~T}_{\mathrm{r} 2} & =\frac{\mathrm{P}_{\mathrm{r} 2} \mathrm{~V}_{\mathrm{r} 2}}{\mathrm{Rm}_{\mathrm{r} 2}}
\end{aligned}
$$

An extrapolated linear curve is drawn through temperature values $T_{\mathrm{r} 1}$ and $\mathrm{T}_{\mathrm{r} 2}$ defining the regenerator interface temperature $\mathrm{T}_{\mathrm{r}-\mathrm{f}}, \quad \mathrm{T}_{\mathrm{r}-\mathrm{r}}$ and $\mathrm{T}_{\mathrm{r}-\mathrm{h}}$, as follows (Tlili et al. 2006):

$$
\begin{aligned}
& \mathrm{T}_{\mathrm{r}-\mathrm{f}}=\frac{3 \mathrm{~T}_{\mathrm{r} 1}-\mathrm{T}_{\mathrm{r} 2}}{2} \\
& \mathrm{~T}_{\mathrm{r}-\mathrm{r}}=\frac{\mathrm{T}_{\mathrm{r} 1}+\mathrm{T}_{\mathrm{r} 2}}{2} \\
& \mathrm{~T}_{\mathrm{r}-\mathrm{h}}=\frac{3 \mathrm{~T}_{\mathrm{r} 2}-\mathrm{T}_{\mathrm{r} 1}}{2}
\end{aligned}
$$

According to the flux direction of the fluid, the interface's temperatures: $\mathrm{T}_{\mathrm{c}-\mathrm{f}}, \mathrm{T}_{\mathrm{f}-\mathrm{r}}, \mathrm{T}_{\mathrm{r}-\mathrm{h}}$ and $\mathrm{T}_{\mathrm{h}-\mathrm{d}}$ were defined by Tlili et al. (2005) as follows:

$$
\begin{aligned}
& \text { If } \dot{\mathrm{m}}_{\mathrm{c}-\mathrm{f}}>0 \text { then } \mathrm{T}_{\mathrm{c}-\mathrm{f}}=\mathrm{T}_{\mathrm{c}} \\
& \text { Otherwise } \mathrm{T}_{\mathrm{c}-\mathrm{f}}=\mathrm{T}_{\mathrm{f}} \\
& \text { If } \dot{\mathrm{m}}_{\mathrm{f}-\mathrm{r}}>0 \text { then } \mathrm{T}_{\mathrm{f}-\mathrm{r}}=\mathrm{T}_{\mathrm{f}} \\
& \text { Otherwise } \mathrm{T}_{\mathrm{f}-\mathrm{r}}=\mathrm{T}_{\mathrm{r}-\mathrm{f}} \\
& \text { If } \dot{\mathrm{m}}_{\mathrm{r}-\mathrm{h}}>0 \text { then } \mathrm{T}_{\mathrm{r}-\mathrm{h}}=\mathrm{T}_{\mathrm{r}-\mathrm{h}} \\
& \text { Otherwise } \mathrm{T}_{\mathrm{r}-\mathrm{h}}=\mathrm{T}_{\mathrm{h}} \\
& \text { If } \dot{\mathrm{m}}_{\mathrm{h}-\mathrm{d}}>0 \text { then } \mathrm{T}_{\mathrm{h}-\mathrm{d}}=\mathrm{T}_{\mathrm{h}} \\
& \text { Otherwise } \mathrm{T}_{\mathrm{h}-\mathrm{d}}=\mathrm{T}_{\mathrm{d}}
\end{aligned}
$$

Where $T_{c-f}$ is the temperature of the interface between the compression space and the cooler, $\mathrm{T}_{\mathrm{f}-\mathrm{r}}$ is the temperature of the interface between the cooler and the regenerator, $\mathrm{T}_{\mathrm{r}-\mathrm{h}}$ is the temperature of the interface between the regenerator and the heater, $\mathrm{T}_{\mathrm{h}-\mathrm{d}}$ is the temperature of the interface between the heater and the expansion space.

The matrix temperatures are so given by:

$$
\begin{aligned}
& \frac{d T p a_{r 1}}{d t}=-\frac{\delta Q_{r 1}}{C_{p r} d t} \\
& \frac{d T p a_{r 2}}{d t}=-\frac{\delta Q_{r 2}}{C_{p r} d t}
\end{aligned}
$$

The heat is transferred toward the working gas by forced convection. The convection equation is given by:

$\delta Q=h A_{a}\left(T_{a}-T\right) d t$

By taking into accounts the conduction loss in the heat exchangers and the regenerator effectiveness, the exchanged can be written as:

$\left\{\begin{array}{l}\delta \mathrm{Q}_{f}=\lambda_{\mathrm{f}} \mathrm{A}_{\mathrm{pa}-\mathrm{f}}\left(\mathrm{T}_{\mathrm{pa}-\mathrm{f}}-\mathrm{T}_{\mathrm{f}}\right) \mathrm{dt} \\ \delta \mathrm{Q}_{r 1}=\lambda_{\mathrm{r} 1} \mathrm{~A}_{\mathrm{pa}-\mathrm{r} 1}\left(\mathrm{~T}_{\mathrm{pa}-\mathrm{r} 1}-\mathrm{T}_{\mathrm{r} 1}\right) \mathrm{dt} \\ \delta \mathrm{Q}_{r 2}=\lambda_{\mathrm{r} 2} \mathrm{~A}_{\mathrm{pa}-\mathrm{r} 2}\left(\mathrm{~T}_{\mathrm{pa}-\mathrm{r} 2}-\mathrm{T}_{\mathrm{r} 2}\right) \mathrm{dt} \\ \delta \mathrm{Q}_{h}=\lambda_{\mathrm{h}} \mathrm{A}_{\mathrm{pa}-\mathrm{h}}\left(\mathrm{T}_{p a-h}-\mathrm{T}_{h}\right) \mathrm{dt}\end{array}\right.$

The partitions of the heating device and the cooler are maintained constants at $\mathrm{Tp}_{\mathrm{a}-\mathrm{h}}$ and $\mathrm{Tp}_{\mathrm{a}-\mathrm{f} .}$ The regenerator temperature varies and depends on the energy absorbed, or provided during the time. The speed of variation of this temperature depends on the calorific capacity of the regenerator.

$d T_{\text {par } 1}=-\frac{d Q_{r 1}}{C_{m r}}$
$d T_{\text {par } 2}=-\frac{d Q_{r 2}}{C_{m r}}$

Since there is a variable pressure distribution throughout the machine, we have arbitrarily chosen the compression space pressure $\mathrm{P}_{c}$ as the baseline pressure. Thus, at each increment of the solution, $P_{c}$ will be evaluated from the relevant differential equation, and the pressure distribution is determined with respect to $\mathrm{P}_{\mathrm{c}}$. It can be obtained from the following expression (Tlili et al. 2006):

$$
\begin{aligned}
& P_{f=P_{c}}+\frac{\Delta P_{f}}{2} \\
& P_{r 1}=P_{f}+\frac{\left(\Delta P_{f}+\Delta P_{r 1}\right)}{2} \\
& P_{r 2}=P_{r 1}+\frac{\left(\Delta P_{r 1}+\Delta P_{r 2}\right)}{2} \\
& P_{r e c h}=P_{r 2}+\frac{\left(\Delta P_{r 2}+\Delta P_{h}\right)}{2} \\
& P_{e}=P_{h}+\frac{\Delta P_{h}}{2}
\end{aligned}
$$

In order to determine the mass of gas in the different interfaces, we considered the mass conservation equation (Tlili et al. 2006).

$$
\begin{aligned}
& d m_{f}=\left(\begin{array}{ll}
\mu A_{c-f}-\mu A_{f-r}
\end{array}\right) d t \\
& d m_{r 1}=\left(\begin{array}{ll}
\mu A_{f-r}-\mu A_{r 1-r 2}
\end{array}\right) d t \\
& d m_{r 2}=\left(\begin{array}{ll}
\mu A_{r 1-r 2}-\mu A_{r-h}
\end{array}\right) d t \\
& d m_{h}=\left(\begin{array}{ll}
\mu A_{r-h}-\mu A_{h-e}
\end{array}\right) d t
\end{aligned}
$$

In the quasi-stationary model, the friction forces are considered equal to the contrary of the pressure forces, and we don't have any acceleration of the working gas. Then, we obtain: 
$F+\Delta P A=0$

The viscous dissipation "Diss" represents the internal generation of heat when the working fluid is forced to flux out while undergoing a rubbing:

$$
\text { Diss }=F U
$$

We know that: $U=\frac{G}{\rho}$

By substituting Eqs. (13) and (14):

Diss $=-\frac{\Delta P G A}{\rho}$

Thus, the energy equation introducing the flux of dissipation is writing as:

$$
\begin{aligned}
\delta Q-D i s s+\left(C_{p} T_{e} u\right. & \left.A_{e}-C_{p} T_{s} u A_{s}\right) \\
& =\delta W+C_{v} d(m T)
\end{aligned}
$$

This equation is applied to the different compartments of the Stirling machine. The sum of the equations found gives the following quantities:

$$
d P_{c}=\frac{\left(R(\delta Q-D i s s)-C_{p} \delta W\right)}{C_{v} V}
$$

Where:

$$
\begin{aligned}
& \delta Q=\delta Q_{f}+\delta Q_{r 1}+\delta Q_{r 2}+\delta Q_{h} \\
& \text { Diss }=\text { Diss }_{f}+\text { Diss }_{r 1}+\text { Diss }_{r 2}+\text { Diss }_{h} \\
& \delta W=P_{c} d V_{c}+P_{e} d V_{e} \\
& V=V_{c}+V_{f}+V_{r 1}+V_{r 2}+V_{h}
\end{aligned}
$$

Befor applying his model to the studied Stirling machine we have applied it to the GPU-3 Stirling machine find in the literature. The relived model results are similar to those find in the literature.

\section{EXPERIMENTAL DEVICE}

The considered experimental device is a reversible thermal machine (motor and/or receiver) that operates between 2 sources of heat at constant temperatures. It works according to the Stirling cycle. The receiver Stirling machine can run either in heat pump, or on a refrigerating machine. The Stirling machine is realized due to the contribution of a heat amount by joule effect in the hot room situated on the machine head (Fig. 1). The cold source is achieved thanks to an open water circuit surrounding the cold room at about $15^{\circ} \mathrm{C}$. It maintains it at constant temperature.

This Stirling motor is a beta type machine. It is designated by an arrangement in only one cylinder. The displacer piston controls the variations of the hot room's volume. The machine piston provokes the variations of volume in the cold room. The variations of hot and cold room's volumes are created by the conjugated action of both pistons.

The photo (Fig.3) illustrates this experimental prototype. It shows the geometry of the displacer piston in which is inserted a plait of copper playing the role of regenerator.
The considered working gas is air, which is assumed to behave like a perfect gas. The regenerator, which is bound to the displacement piston, is constituted of two coaxial tubes in steel. The internal tube is filled of copper that plays the role of heat accumulator material (porous media).

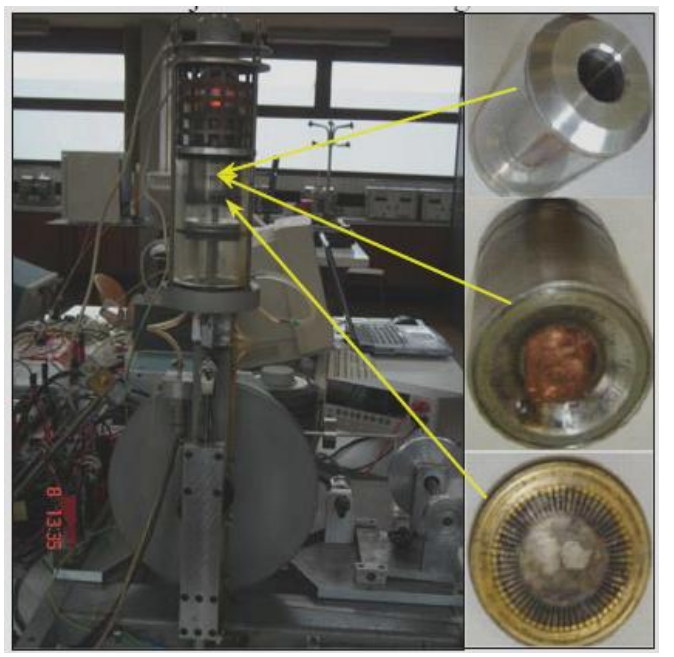

Fig. 3. Photography of the Stirling motor showing the composition of the regenerator

For the metrology, this thermal machine is equipped with pressure transducer, volume transducer, and thermocouples, as well as a tachometer. This latter, allows us to determine the Stirling machine rpm. The volume transducer, initially calibrated, determines the evolution versus time of the total air volume trapped in the two rooms as well as in the regenerator. It delivers a signal of continuous tension. Its maximum corresponds to $V_{\max }=300 \mathrm{~cm}^{3}$ and the minimum corresponds $V_{\min }=160 \mathrm{~cm}^{3}$. Voltage delivered by this transducer is proportional to the volume of gas shut in the thermal machine. To determine the pressure inside the cold room, a differential pressure transducer (calibrated initially) is also installed. Voltage delivered by this transducer is proportional to the pressure of gas shut in the cold room. Thus, the pressure signal in the hot room can be deducted easily from the one acquired in the cold room. For the thermocouples, we have $\pm 0.1^{\circ} \mathrm{C}$ of incertitude of the measured temperatures. For the pressure transducer, we note $0.2 \%$ of incertitude of the measured pressure and for the position transducer we note $5.10^{-3} \mathrm{~m}$ of incertitude.

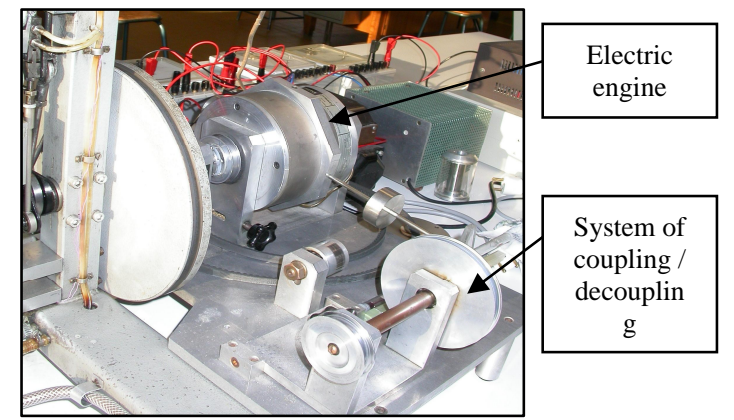

Fig. 4. Coupling / decoupling system of the Stirling machine 
Table 1 Parameters and characteristics of the experimental

\begin{tabular}{|l|c|l|c|}
\hline $\begin{array}{l}\text { Compressio } \\
\text { Space }\end{array}$ & Regenerator & \\
\hline Diameter & $80 \mathrm{~mm}$ & Diameter & $50 \mathrm{~mm}$ \\
\hline Height & $\begin{array}{l}120 \\
\mathrm{~mm}\end{array}$ & Height & $85 \mathrm{~mm}$ \\
\hline $\begin{array}{l}\text { Expansion } \\
\text { Space }\end{array}$ & $70 \mathrm{~mm}$ & $\begin{array}{l}\text { Hot } \\
\text { Temperature }\end{array}$ & $673 \mathrm{~K}$ \\
\hline $\begin{array}{l}\text { Diameter } \\
\text { Height }\end{array}$ & $\begin{array}{l}\text { Cold } \\
\text { Temperature }\end{array}$ & $297 \mathrm{~K}$ \\
\hline $\begin{array}{l}\text { Working } \\
\text { fluid }\end{array}$ & Air & Rotation speed & $180 \mathrm{rpm}$ \\
\hline
\end{tabular}

The noted incertitude's values are small compared to the measurement ranges and calculations. The thermal machine (Fig. 4) is coupled to an auxiliary electric motor. It is driven either in trigonometric sense as heat pump or in hourly sense as refrigerator. Constructions details of this machine are given in Table 1 .

\section{RESUlTS AND DISCUSSIONS}

\subsection{Experimental study of driving machine}

During the experiments, the ambient temperature was between $23{ }^{\circ} \mathrm{C}$ and $25{ }^{\circ} \mathrm{C}$. The temperature of the working fluid in the hot and the cold rooms are respectively about $536^{\circ} \mathrm{C}$ and $50^{\circ} \mathrm{C}$.

The gap of temperature between the inside of the machine and the outside is considerable.

A significant calorific power loss occurs mainly because of the radiation. The calorific power loss is proportional to the temperature of the hot source, and inversely proportional to the cold source one. Why we thought to isolate the hot room by a reflector. This latter plays the role of an anti-radiantion filter. In this paper, we will study two configurations (Fig. 5): without insulation, and with insulation of the hot room.

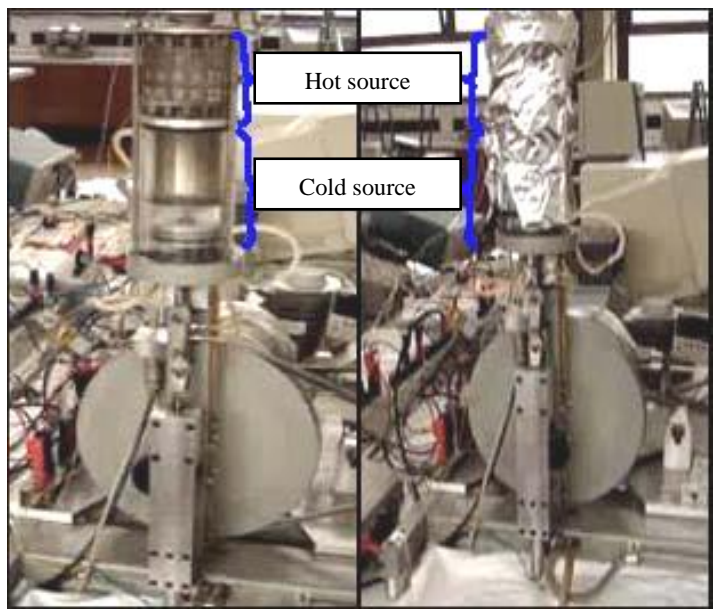

Fig. 5. Photography of the Stirling motor with and without insulation of the hot source

\subsubsection{Variations of the Machine Rotation Speed}

For both studied configurations, the motor rotation speed is deduced from the square signal delivered by a photoelectric cell placed facing the inertia wheel. The signal frequency specter allows us to pick the frequency characteristic. The rotation speed of the machine is of $3.78 \mathrm{rps}(226.8 \mathrm{rpm})$ for the non isolated case, and of $3.92 \mathrm{rps}(235.3 \mathrm{rpm})$ for the isolated case (for the same experimental conditions).

According to these results, the machine velocity increases about $4 \%$. This increase is essentially owed to the increase of the hot room temperature after its thermal insulation. It causes the increase of the pressure in the hot space too.

\subsubsection{Experimental and Theoretical Volume Variation}

The variations of the machine volumes are shown in Fig. 6. The volume follows a sinusoidal evolution, it has a maximum of $V_{\max }=300 \mathrm{~cm}^{3}$, and a minimum of $V_{\min }=160 \mathrm{~cm}^{3}$. By comparing Fig. 6 and Fig. 7, we observe that experimental and theoretical volume variations present great difference. This latter can be explained by the speed of experimental volume variations (great rotation speed of the machine).

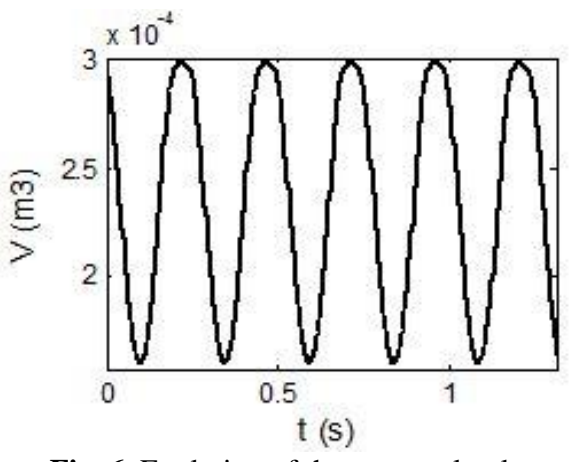

Fig. 6. Evolution of the temporal volume (with and without insulation)

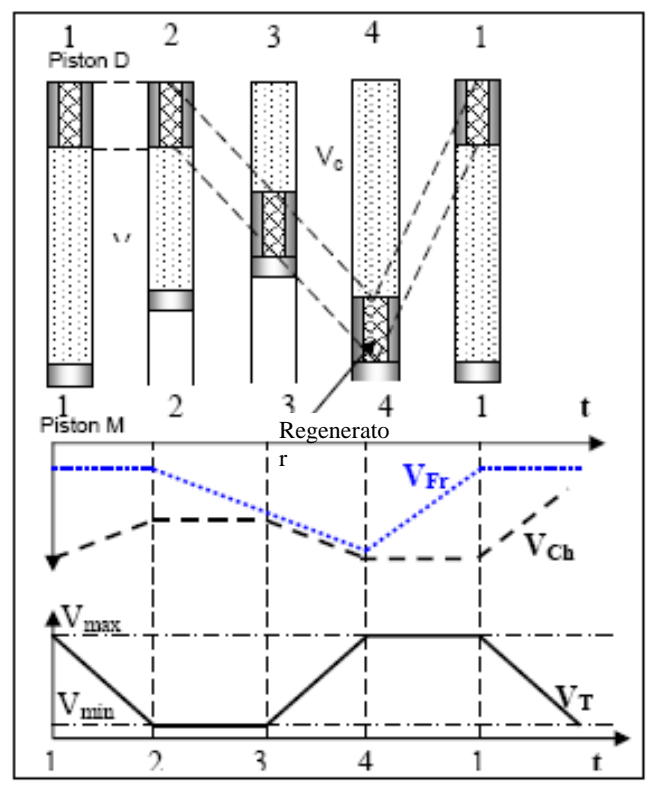

Fig.7. Theoretical variations of the different volumes 


\subsubsection{Experimental Variation of Cold and Hot Room's} Temperatures

The hot room is heated by an electric resistance (Joule effect), where the total delivered calorific power is about $250 W$.

For the isolated case, the temperatures of the cold and hot sources are respectively of $52{ }^{\circ} \mathrm{C}$ (Fig. 8a) and of $545^{\circ} \mathrm{C}$ (Fig. 9a). The fluctuations of these temperatures (Fig. 11a) are sinusoidal and about $3^{\circ} \mathrm{C}$ of amplitude.
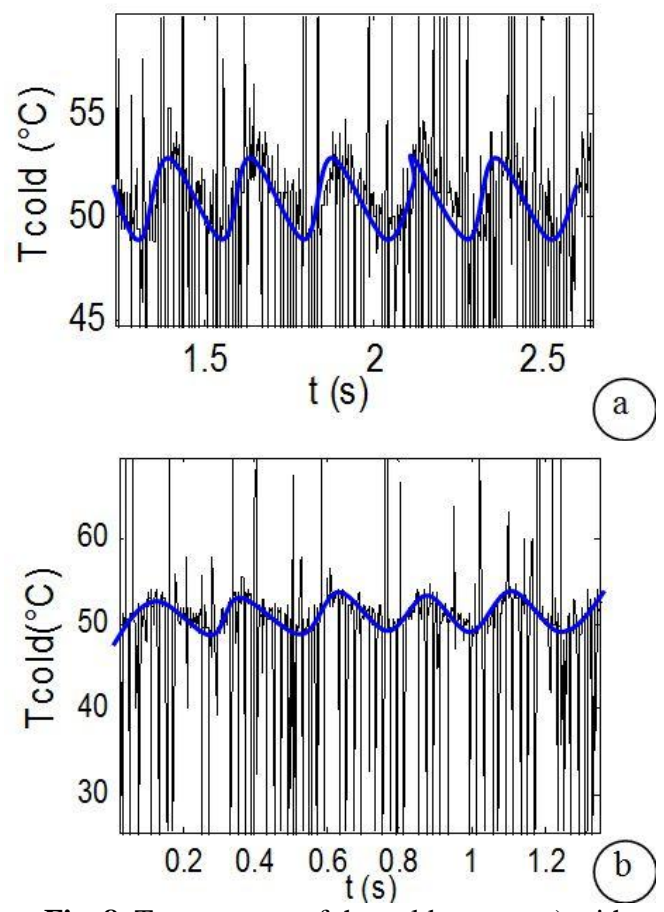

Fig. 8. Temperature of the cold source: a) without insulation; b) with insulation
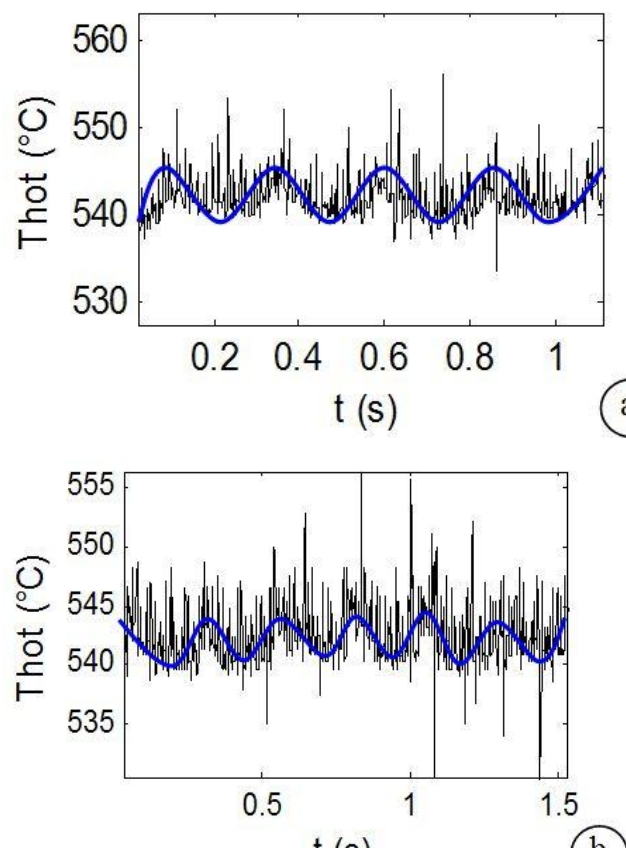

$t(s)$

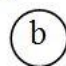

Fig. 9. Temperature of hot source: a) without insulation; b) with insulation
For the isolated case, the temperatures of the cold and hot sources are respectively of $50{ }^{\circ} \mathrm{C}$ (Fig. 8b) and of $538{ }^{\circ} \mathrm{C}$ (Fig. 9b). The fluctuations of temperatures (Fig. 10a) are sinusoidal and about $4^{\circ} \mathrm{C}$ of amplitude.

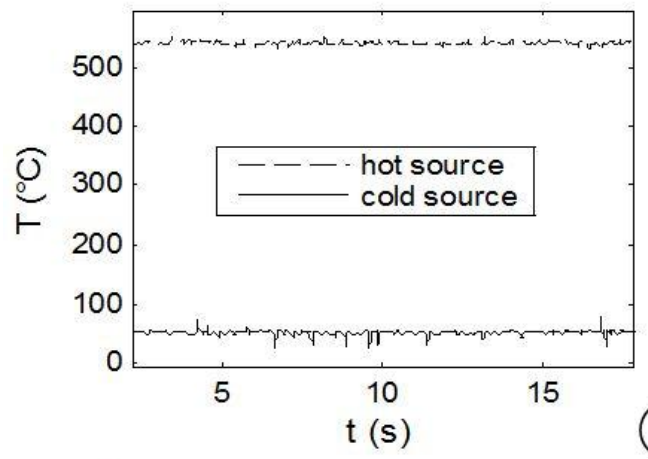

(a)

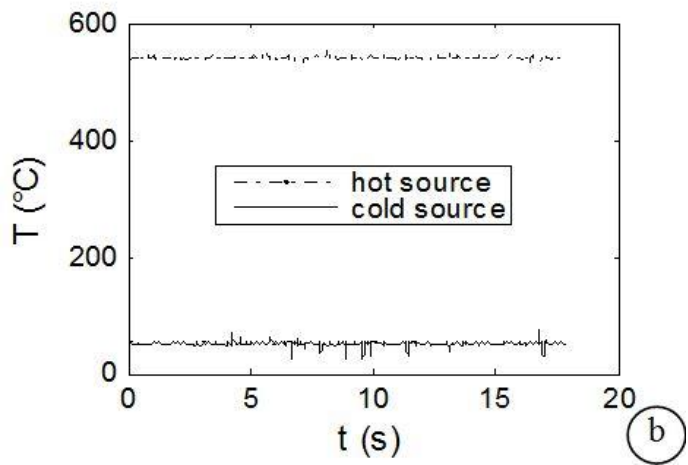

Fig. 10. Temperatures of hot and cold sources: a) without insulation; b) with insulation

The gap of temperatures between the two sources is constant and important. This difference may be explained by the presence of the regenerator, which causes a thermal fence between the two sources. After insulation, the temperature of hot room increase of $7{ }^{\circ} \mathrm{C}$ over the non isolated case, and the temperature of the cold source decreases of about $2{ }^{\circ} \mathrm{C}$. These temperature changes seem enough logical, and can be explained by the reduction of the thermal radiation losses due to the installation of the anti-radiation filter on the external layer of the hot source.

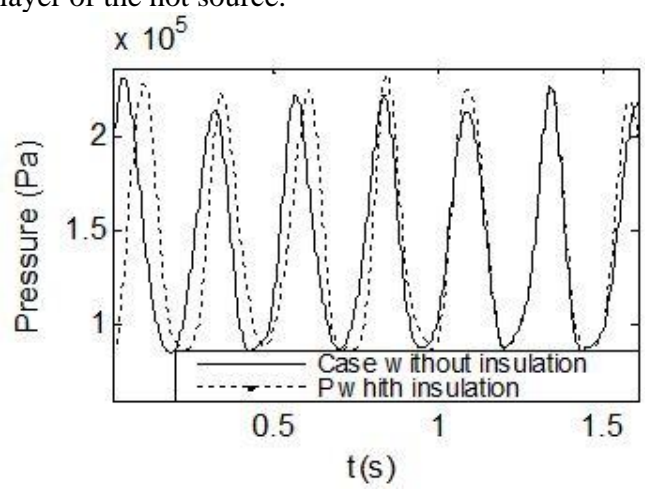

Fig. 11. Evolution of pressure of isolated and none isolated cases

\subsubsection{Experimental Variation of the Pressure}

An example of temporal evolution of the pressure for both studied cases is presented in the Fig. 11. For the non isolated case, the sinusoidal evolution of the absolute pressure shows that the signal fluctuates 
between a maximum of about 2.2 bars and a minimum of about $0.9 \mathrm{bar}$.

For the isolated case, and for the same experimental conditions (same calorific power as the non isolated case), the pressure increases slightly. The insulation of the hot room causes the increase of the temperature, and therefore the increase of the pressure.

\subsubsection{P-V Diagram}

The work developed by the motor machine during one cycle is given by the following expression:

$W=\int_{V_{\min }}^{V_{\max }}-p d V$

This work depends of the simultaneous variations of the pressure and the volume.

From the acquirements of the signals of pressure and volume in steady regime, we can get work from the $\mathrm{p}-\mathrm{V}$ diagram. The work developed by the machine is just the area of the closed curve. The Figs. 12a and $12 \mathrm{~b}$ give this work respectively for the isolated and the non isolated case.
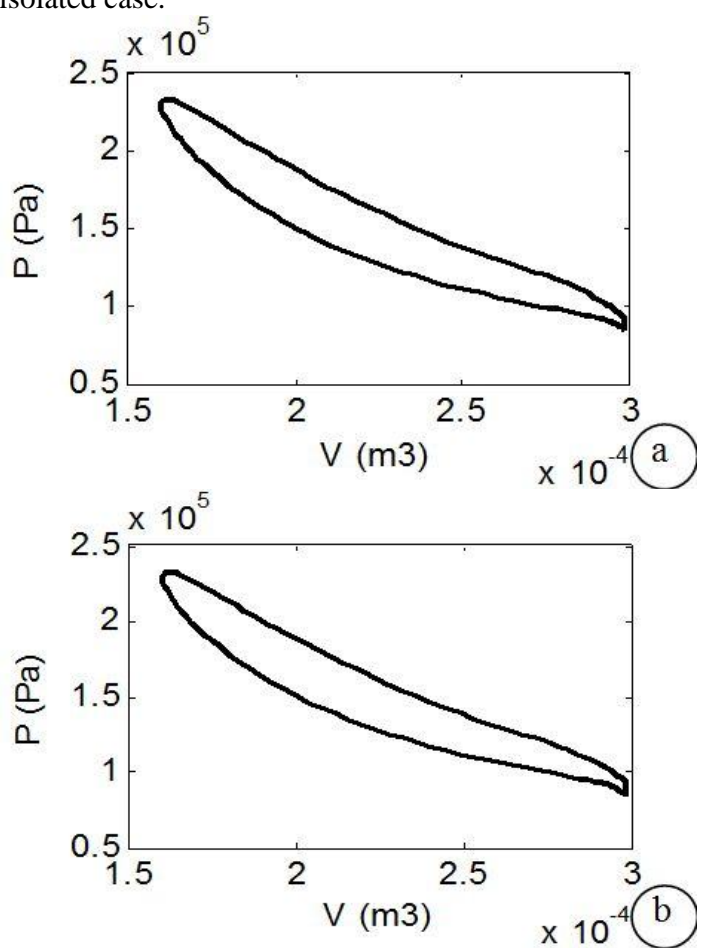

Fig. 12. p-V diagrams: a) with insulation; $b$ ) without insulation

According to these evolutions, and considering the rotation speed of the machine, the power developed by the Stirling machine is respectively of $10.4 \mathrm{~W}$ for the non isolated case and $11.2 \mathrm{~W}$ for the isolated one. Referring to the previously theoretical model, we determined the theoretical cycle by the $\mathrm{p}-\mathrm{V}$ diagram (Fig. 13).

To get theoretical work, we imposed the experimental temperatures of the respectively hot and cold sources to $535^{\circ} \mathrm{C}$ and to $51^{\circ} \mathrm{C}$. We plotted the theoretical P-V and calculated its surface. We get a theoretical power of 88
$W$, which is about 8 times more important than the experimental one $(11.2 \mathrm{~W})$.

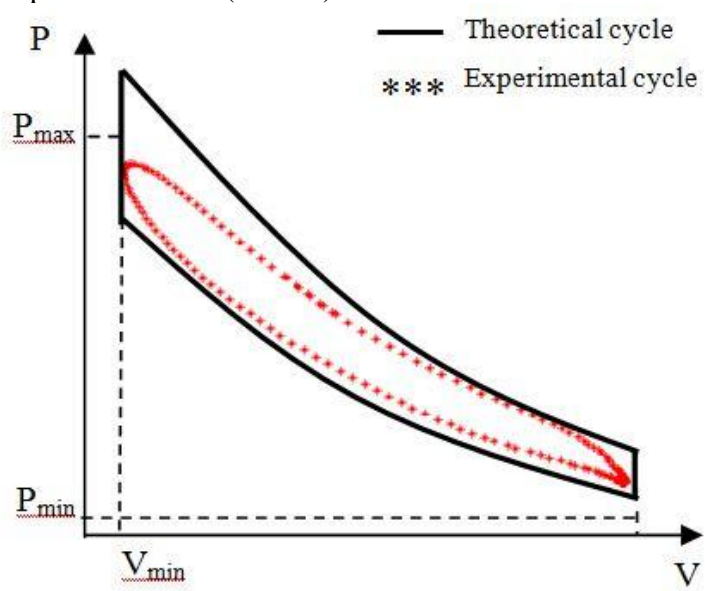

Fig. 13. Theoretical or experimental $\mathrm{p}-\mathrm{V}$ diagrams

The vast difference between these two results is mainly due to the failing of the theoretical model. Indeed, in this model, we neglected the thermal losses whereas they dissipate $68 \%$ of the heating power.

\subsubsection{Comparison between Theoretical and Experimental P-V Diagrams}

According to the Fig. 13, the cycle in continuous line is the ideal Stirling one. The cycle in dotted line is the real one; witch has been given experimentally. An important difference between both cycles (experimental and theoretical) can be noted. These differences are essentially explained by:

- Losses by friction and by singular pressure drop when the working fluid out-fluxs in the heat exchangers.

- The real continuous movements of the pistons are different from the theoretical movements (Wu et al. 1998).

- The great heterogeneity of the instantaneous temperatures in the thermal machine and to the irreversibility presents in the Stirling machine (Kaushik et al. 2001).

- The regenerator cannot follow the temperatures variations from the hot side to the cold one, and viceversa. Indeed, the temperature of the regenerator reaches that of the hot source and does not fall anymore because of its big thermal inertia (Kildegard 2006).

- The loss of the pressure drop recorded in the regenerator is important. It is due to its geometric aspects (weak diameter) and to its physical characteristic (weak porosity). But in spite of the important singular pressure drop, the regenerator remained a very important element for the improvement of the Stirling machine power. In fact, the regenerator functions like a thermodynamic sponge that absorbs and reject the heat alternately (Reader 1983). It is constituted usually of a porous material where it function is to increase the contact surface between the working fluid and the regenerator matrix. The features of the regenerator matrix are: a big surface of contact with working fluid, elevated thermal conductivity and weak density in order to minimize the dead volumes and to improve the quotient between the extreme pressures. 
4.1.7 Evolution of Experimental Pressure Upstream and Downstream the Regenerator for the non Insulated Case

The Fig. 14 gives the evolution of the absolute pressure of the working gas upstream and downstream the regenerator. We note that the two pressures present a sinusoidal evolution, and are in opposition of phases.

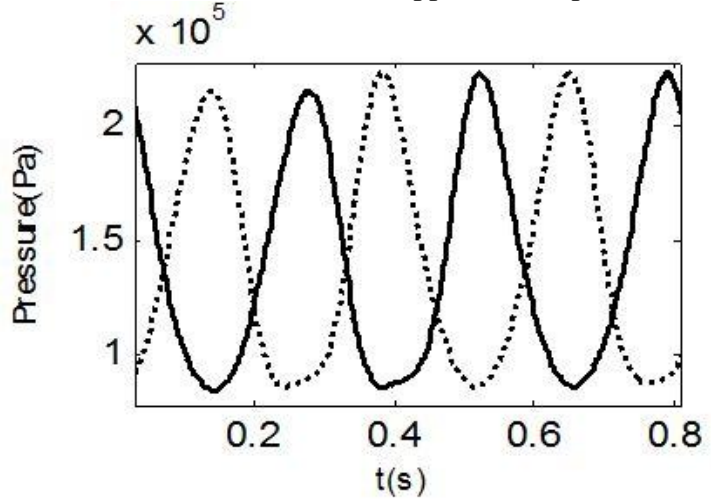

Fig. 14. Evolution of the pressure upstream and downstream the regenerator

The fall of pressure through the regenerator can be gotten by subtraction between the signals upstream and downstream (Fig. 15). The obtained difference has a sinusoidal and centered evolution, varying from -1.45 to +1.45 bars. This pressure fall is due to the porous matrix of the regenerator, which presents oddness when it is crossed by the working fluid.

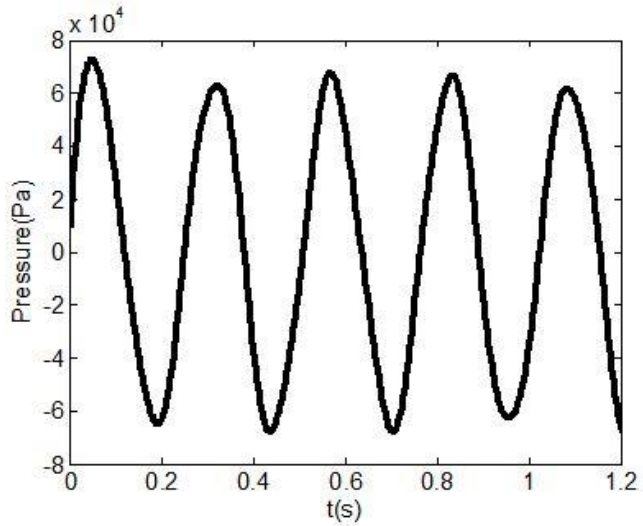

Fig. 15. Evolution of the pressure drop through the regenerator

\subsection{Experimental Study of the Receiving Mode}

\subsubsection{Experimental Evolution of Volume and Pressure}

The Figs. 16a and 16b represent the evolution of the pressure and volume within the refrigerator and the heat pump. The evolutions of volumes for the two configurations are identical. The obtained variations are sinusoidal and similar to the theoretical one. Moreover, they are varying from $160 \mathrm{~cm}^{3}$ (minimal volume) to $300 \mathrm{~cm}^{3}$ (maximal volume). On the same graph, we drew the variations of the pressure.

For the refrigerator, the pressure has as an average value of $1.13 \mathrm{bar}$ for $N=177 \mathrm{rpm}$, whereas it is of 1.372 bars for $N=174 \mathrm{rpm}$ for the heat pump. The pressure in the heat pump is higher than the pressure in the refrigerator. This is explained by the difference in temperatures recorded in both configurations. Indeed, the recorded temperatures in the heat pump are more significant than those obtained in the refrigerator case.
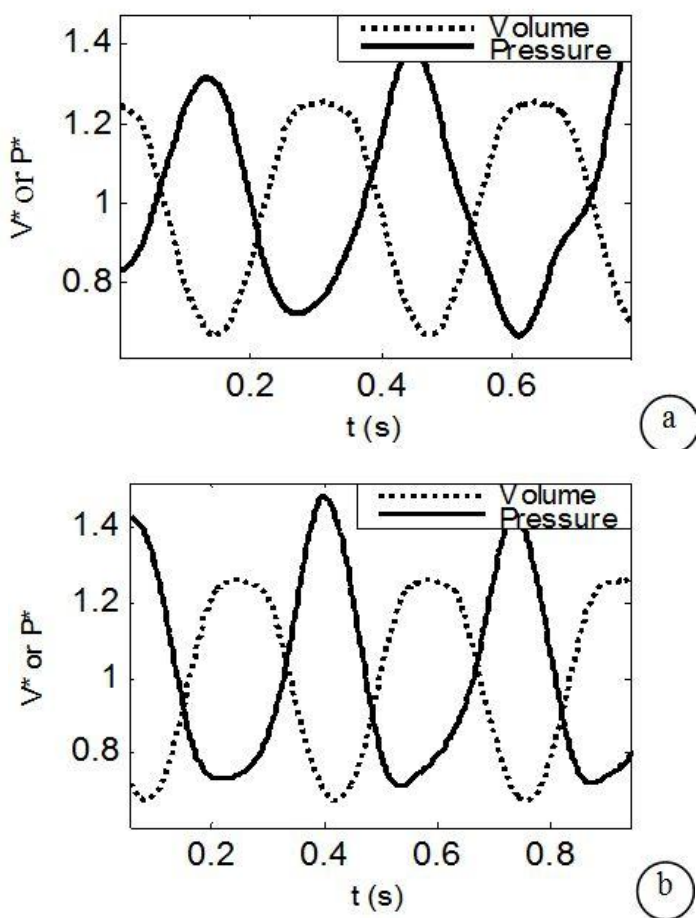

Fig. 16. Evolution of dimensionless pressure and volume: a) Refrigerator; b) heat pump
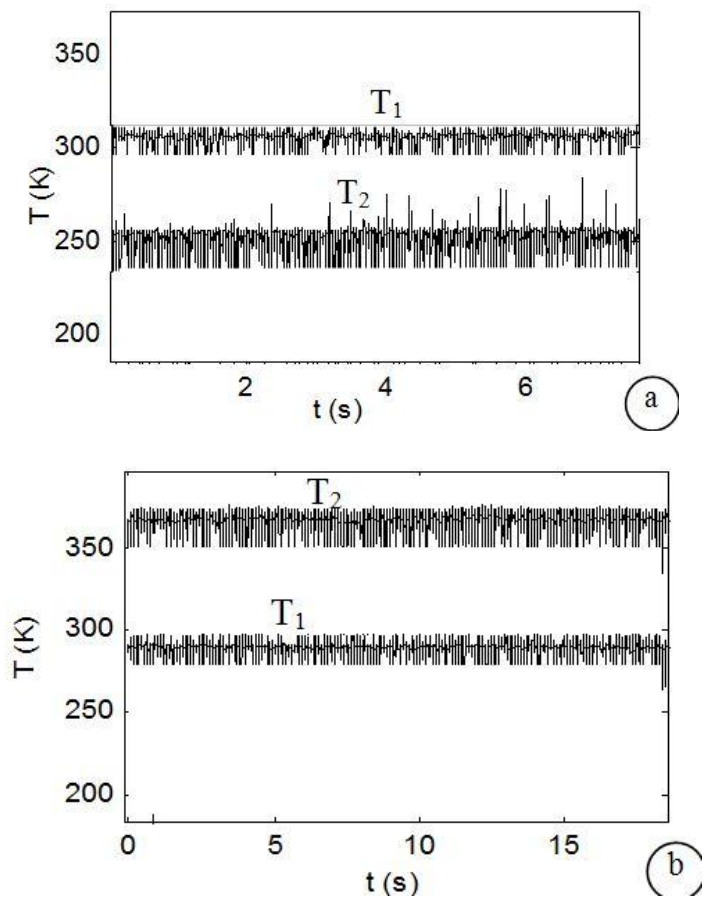

Fig. 17. Evolution of sources temperatures: a) Refrigerator; b) Heat pump

\subsubsection{Experimental Evolution of Temperatures}

In Figs. $17 \mathrm{a}$ and $17 \mathrm{~b}$, we plotted the temperatures evolution of the heat sources. For the heat pump, the temperatures of the two sources are practically constant. 
The temperature of the cold source is of $16{ }^{\circ} \mathrm{C}$, whereas that of the hot source is of $94{ }^{\circ} \mathrm{C}$. In the same way for the refrigerator, the temperatures are constant with an average value of $-21^{\circ} \mathrm{C}$ for the cold room and of $34^{\circ} \mathrm{C}$ for the hot one. By examining both graphs, we remark that the two sources are reversed. $T_{1}$ is the temperature of the cold room for the refrigerator, and it becomes the temperature of the hot one for the heat pump. This is explained by the change of the rotation direction of the electric motor. Heat is pumped upwards for the refrigerator and downwards for the heat pump.

By examining in detail the signal, we note that the temperatures of the two sources follow almost sinusoidal evolutions. These evolutions are generated by the sinusoidal variations of the volumes and the pressure.

The obtained signals are not perfectly sinusoidal, because of the response time of each thermocouple. It is also related to the initial signal which is very disturbed and to the numerical filter which was adopted, and which is not well adapted to such temperature signals.

\subsection{3 p-V Diagrams}

The Figs. 18a and 18b represent P-V diagrams of the heat pump and the refrigerator. It is noticed that the diagram for the heat pump is broader than that of the refrigerator. The total work of all cycles is approximately about $4.4 \mathrm{~J}$ for the heat pump and of $3.65 \mathrm{~J}$ for the refrigerating machine. It should be noted here that this difference is due mainly to the difference in temperatures on the level of the heat sources. Indeed, this difference in temperature causes the increase of the pressure.
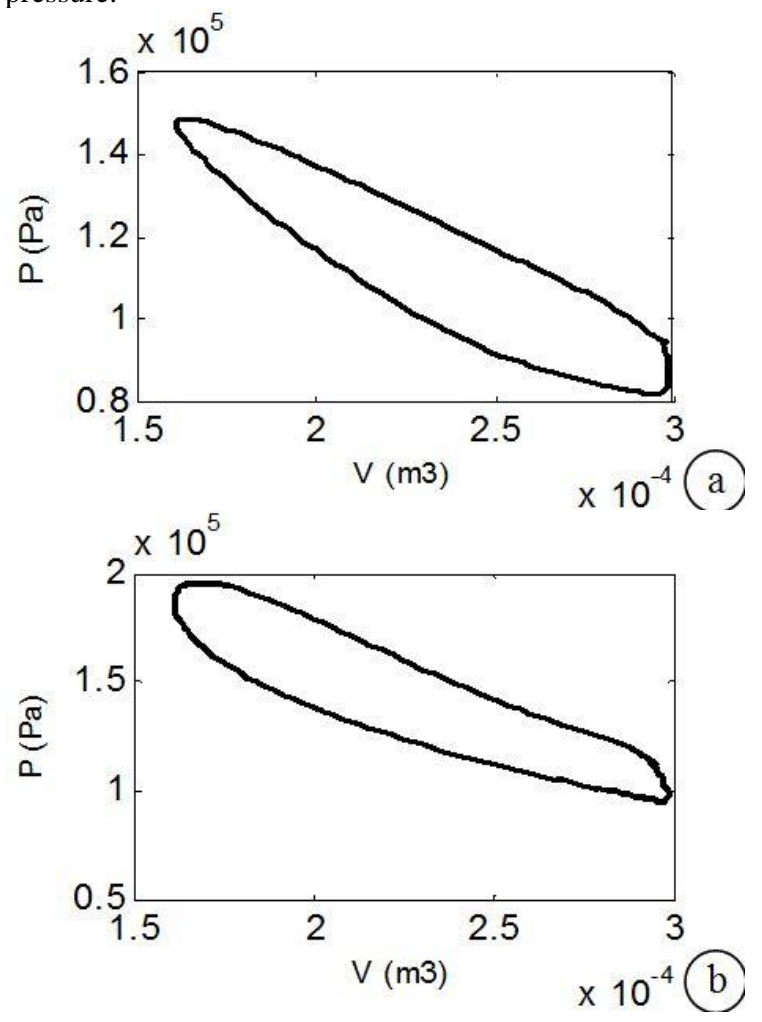

Fig. 18. p-V diagrams: a) Heat pump; b) Refrigerator
Table 2 Comparative table of the quasi-steady models (GPU-3)

\begin{tabular}{|c|c|c|}
\hline & Power $(\mathrm{Kw})$ & Efficiency $(\%)$ \\
\hline Literature results & 6.324 & 53.3 \\
\hline Our results & 6.320 & 53.27 \\
\hline Experimental & 3.96 & 35 \\
\hline
\end{tabular}

For the refrigerant machine or heat pump, we must impose a mechanical work to the system in order to transform it in quantity of heat by exchange of energy.

In our case, we have measured this work by using the Clapeyron Diagram (integral of - p.dV). This experimental quantity is equal to $4.4 \mathrm{~J}$. We have injected this value in our model. The temperatures (which characterize quantities of heat of the cold and heat sources) given by this model are about $65 \%$ greater than the experimental ones.

The great recorded difference is mainly due to the lack of precision of the quasi-steady model. In this model, we didn't take into consideration frictions in the mechanical links, losses by transmission and aerodynamic losses. Indeed, these losses are firstly difficult to be formulated, and secondly decrease the pressure of the working gas between the compression space and the expansion one. They are also at the origin of the reduction of the refrigerated capacity and the refrigerator (the $\mathrm{COP}$ ).

\subsection{Validation}

In order to check the validity of the developed model, we have applied it model to the GPU-3 Stirling machine. The GPU-3 is a General Motor Stirling machine prototype, described in the literature (Tlili et al. 2006) and (Timoumy et al. 2008).

The Table 2 resumes our results and literature theoretical and experimental results (Tlili 2001) for the GPU-3 Stirling machine.

By examining our theoretical and experimental results, we have remark a difference between them. Indeed, the Fig. 19 is an illustration of the theoretical pressure evolution and the experimental one. It is noticed that the two curves have the same pace. The found theoretical pressure is of an average value of 2.17 bars, whereas it is only of 1.417 bars in the experimental case. This difference in pressure is explained by the pressure losses

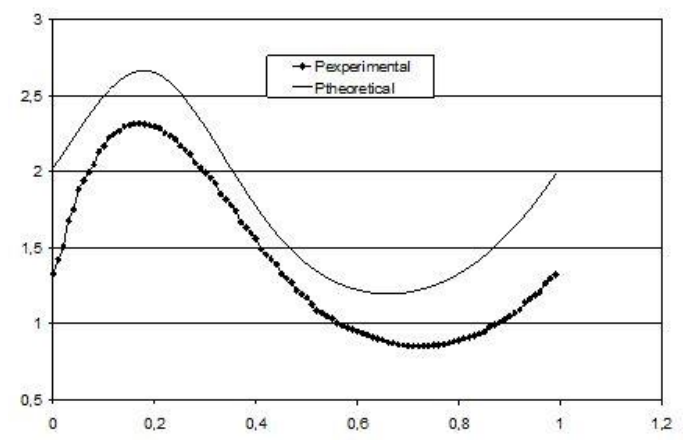

Fig. 19. Evolution of experimental and theoretical pressure 


\section{Conclusions}

A beta type Stirling machine is adopted for theoretical and experimental study. The Stirling machine is tested for two modes: driving and receiving machine. For various tests, we took several measurements by raising the signals of temperatures, pressure and volume in quasi-steady model. We traced the evolutions of the various parameters as well as the $\mathrm{p}-\mathrm{V}$ diagrams for each mode. The interpretation of the various graphs enabled us to illustrate out the importance of the regenerator in adding new quantity of heat to the machine, although it is the seat of significant pressure loss.

We concluded by comparing between the model results and those measured, that there is a good agreement between them.

\section{REFERENCES}

Al-Hazmy, M.M., (1998). A Computational Model For Resonantly-Coupled Alpha Free-Piston Stirling Coolers, Ph. D. thesis, The Oregon State University, USA.

Berchowitz, D.M., and R. Unger (1991). Experimental performance of a free-piston Stirling cycle cooler for non-CFC domestic refrigeration applications. Proceeding of the XVIII ${ }^{\text {th }}$ International Congress of Refrigeration, Montreal, Canada, 144(10).

Berchowitz, D. M., (1992). Free-piston Stirling coolers for intermediate lift temperatures, Proceeding of ISEC, San Diego, 115-121.

Berchowitz, D.M., (1998). Maximized performance of Stirling cycle refrigerators. International Congress of Refrigeration 4, Oslow, 422-429.

Urieli, I., and D.M. Berchowitz (1982). Stirling Cycle Machine Analysis, Adam Hilger Ltd, Bristol.

Kaushik, S.C., and S. Kumar (2001). Finite time thermodynamic evaluation of irreversible Ericsson and Stirling heat machines. Energy Conversion and Management 42(3), 295-312.

Mancini, T., and P. Heller (2003). Dish Stirling systems: an overview of development and status. ASME Journal of Solar Energy Engineering 135, 135-151.

Nika, Ph., and F. Lanzetta (1997). Évaluation pratique des performances d'une machine Stirling de taille réduite fonctionnant en cycle frigorifique. Journal de Physique III. 1571- 1591.

Organ, A.J., (1997). The Regenerator and The Stirling Machine. J.W. Arrowsmith, Great Britain.

Pertescu, S., M. Coastea, C. Harman and T. Florea (2002). Application of the direct method to irreversible Stirling cycle with finite speed. Energy Conversion, Conservation Environnement Impact. 589-609.

Popescu, G., V. Radcenco, M. Costea and M. Feidt, (1996). Finite time thermodynamics optimisation of an endo-exo-irreversible Stirling Motor. Revue Générale de Thermique 35, 656-661.

Reader, G., and C. Hooper (1983). Les machines Stirling. Edit. E \& F.N. SPON, New Fetter Lane, London.

Stirling, R., (1816). Stirling Air Machine and The Heat Regenerator. Patent no. 4081.

Senft, J.R., (1993). Ringbom Stirling Machines. New York: Oxford University Press. 113-137.

Stig-Kildegard, A., (2006). Numerical study on optimal Stirling machine regenerator matrix designs taking into account the effects of matrix temperature oscillations. Energy Conversion and Management 47, 894-908.

Stine, W.B., and R.B. Diver, (1994). A Compendium of Solar Dish/Stirling Technology. Sandia National Laboratories, Albuquerque, USA.

Timoumi, Y., S. Tlili and S. Ben Nasrallah (2008). Design and performance optimization of GPU-3 Stirling machines. Energy 33, 1100-1114.

Tlili, S., Y. Timoumi, S. Ben Nasrallah (2006). Numerical simulation and losses analysis in a Stirling machine. International Journal of Heat \& Technology 24, 97-105.

Wu, F., L. Chen, Sun F., C. Wu and Z. Yonghong (1998). Performance and optimization criteria for forward and reverse Quantum Stirling cycles. Energy Conversion and Management 39, 733-739. 